\title{
Amino-Acid Residues Involved in Glutamate Receptor 6 Kainate Receptor Gating and Desensitization
}

\author{
Mark W. Fleck, Elizabeth Cornell, and Stephanie J. Mah \\ Center for Neuropharmacology and Neuroscience, Albany Medical College, Albany, New York 12208
}

\begin{abstract}
The glutamate receptor (GluR) agonist-binding site consists of amino acid residues in the extracellular S1 and S2 segments in the $\mathrm{N}$-terminal and M3-M4 loop regions, respectively. Molecular and atomic level structural analyses have identified specific S1 and S2 residues that interact directly with ligands, interact with one another in a dimeric configuration, and influence channel gating and desensitization properties of AMPA receptors. Other studies suggest that KA receptor gating and desensitization may differ mechanistically. In particular, a leucine (L) to tyrosine (Y) mutation in the S1 segment of AMPA receptors is sufficient to block desensitization, whereas KA receptors naturally contain a tyrosine residue at the equivalent position (Y751 in GluR6) but retain the fast-desensitizing phenotype. We hypothesized that KA receptor desensitization is preserved by a compensatory substitution in the S2 segment. We generated a series of GluR6 mutants that converted individual S2 domain residues to their AMPA receptor equivalents. Various S2 mutations had effects on the kinetics of desensitization and recovery from desensitization, but no single amino acid substitution was found to block desensitization, as in the L/Y mutant AMPA receptors, or to prevent desensitization to KA. Other mutations designed to neutralize residues thought to interact across the dimer interface had dramatic effects on channel gating and desensitization. These results are consistent with a close but imperfect structural homology between AMPA and KA receptors and support the role of conserved S1S2 domain interactions at the dimer interface in GluR channel function.
\end{abstract}

Key words: glutamate receptor; binding site; desensitization; S2-segment; dimer; mutagenesis

\section{Introduction}

Glutamate receptor (GluR) ion channels are broadly involved in excitatory synaptic transmission in the mammalian CNS (for review, see Seeburg, 1993; Hollmann and Heinemann, 1994; Dingledine et al., 1999; Lerma et al., 2001). Of these, AMPA receptors are composed of the subunits GluRA-GluRD (Keinanen et al., 1990), alternatively as GluR1-GluR4, respectively (Boulter et al., 1990); kainate (KA) receptors are composed of the subunits GluR5-GluR7 and KA1-KA2 (Bettler et al., 1990; Egebjerg et al., 1991; Werner et al., 1991; Herb et al., 1992; Lomeli et al., 1992; Sakimura et al., 1992). Structurally, each includes a long extracellular N-terminal domain, three transmembrane domains (M1, M3, and M4), a membrane-associated segment (M2), and a cytoplasmic C-terminal domain (see Fig. 1). The ligand-binding domain consists of so-called S1 and S2 segments that together share structural homology with bacterial periplasmic amino acid binding proteins (Oh et al., 1993; O'Hara et al., 1993; Kuryatov et al., 1994; Stern-Bach et al., 1994; Kuusinen et al., 1995; Tygesen et al., 1995; Paas et al., 1996) and link agonist binding to GluR channel opening and desensitization (Armstrong et al., 1998; Lampinen et al., 1998; Abele et al., 2000; Armstrong and Gouaux, 2000).

AMPA and KA receptors desensitize very rapidly within 1-10 msec of exposure to glutamate (Lomeli et al., 1994; Mosbacher et al., 1994; Heckmann et al., 1996; Sekiguchi et al., 1997; Swanson

Received July 23, 2002; revised Nov. 22, 2002; accepted Nov. 25, 2002.

This work was supported by National Institute of Neurological Disorders and Stroke/National Institutes of Health Grant NS40347, the Schaffer Foundation, and a Charles E. Culpeper Pilot Grant from the Rockefeller Brothers Fund. We thank Drs. Mark L. Mayer and Peter Seeburg for the wild-type GluR6 and GluRA cDNAs.

Correspondence should be addressed to Dr. Mark W. Fleck, Center for Neuropharmacology and Neuroscience, Albany Medical College, A-136, 47 New Scotland Avenue, Albany, NY 12208. E-mail: fleckm@mail.amc.edu. Copyright $\odot 2003$ Society for Neuroscience $\quad 0270-6474 / 03 / 231219-09 \$ 15.00 / 0$ et al., 1997; Bowie and Lange, 2002). Despite their structural and functional similarities, AMPA and KA receptors differ in regards to desensitization in several ways. They differ in response to various agonists, most notably to KA that induces a rapidly desensitizing response at KA receptors versus a nondesensitizing response at AMPA receptors (Kiskin et al., 1986; Patneau and Mayer, 1991; but see Patneau et al., 1993). They differ in their sensitivities to allosteric agents such as cyclothiazide and concanavalin A (Con A) (Partin et al., 1993; Wong and Mayer, 1993; Yamada and Tang, 1993) and external ions (Bowie, 2002; Bowie and Lange, 2002) that modulate desensitization. They differ in recovery from desensitization, because KA receptors recover much more slowly than AMPA receptors (Lomeli et al., 1994; Partin et al., 1996; Bowie et al., 2002). Most notably, they differ in the molecular determinants of desensitization; a single leucine (L) to tyrosine $(\mathrm{Y})$ mutation in the $\mathrm{S} 1$ segment prevents AMPA receptor desensitization, whereas this $\mathrm{L} / \mathrm{Y}$ substitution is ineffective at KA receptors that naturally harbor a tyrosine residue in the equivalent position (Y521 in GluR6) (Stern-Bach et al., 1998).

The present study set out to test the homology between AMPA and KA receptors with respect to the molecular determinants of desensitization. We sought to determine whether a compensatory change in the S2 segment of GluR6 either makes or breaks an interaction with the L/Y residue in S1 (Y521) to preserve KA receptor desensitization. We also examined glutamate (Glu)-, KA-, and AMPA-evoked currents at S2 mutant receptors, the kinetics of recovery from desensitization, and the involvement of putative dimerization residues in GluR6 channel gating and desensitization.

\section{Materials and Methods}

Structural analyses, cDNAs, and mutagenesis. GluR2 S1S2 crystal structures were obtained from the Protein Data Bank (PDB) (www.pdb.org) 
and analyzed by a Swiss PDB viewer. Structures examined included the ligand-free dimer (PDB 1FTO) and ligand-bound monomers (PDB 1FTJ, 1FTK, 1FTL, and 1FTM) published by Armstrong and Gouaux (2000). The wild-type GluR6 and GluRA cDNAs in pRK vectors were kindly provided by Drs. Mark L. Mayer (National Institute of Child Health and Human Development/National Institutes of Health, Bethesda, MD) and Peter Seeburg (Max-Planck Institute, Heidelberg, Germany). The plasmid encoding enhanced green fluorescent protein (EGFP) was created by subcloning the EGFP coding sequence from pEGFP (Clontech, Palo Alto, CA) into pRK. GluR mutations were introduced by QuikChange mutagenesis (Stratagene, La Jolla, CA) using PfuTurbo DNA polymerase (Stratagene) and custom primers synthesized by Midland Certified Reagents (Midland, TX) or Sigma Genosys (Woodlands, TX). Complementary mutagenesis primers were 27-33 bases in length and contained 1-3 base substitutions including a novel restriction site for diagnostic purposes. Mutant cDNAs were amplified in transformed DH5 $\alpha$ cells (Life Technologies, Rockville, MD), purified using Qiafilter maxiprep kits (Qiagen, Los Angeles, CA), selected by diagnostic restriction digests (New England Biolabs, Beverly, MA), and confirmed by automated DNA sequencing (Albany Medical Center Molecular Core Facility and Center for Comparative Functional Genomics, The State University of New York, Albany, NY).

Nomenclature. Amino acid residues for all GluRs were numbered relative to the initiation methionine. However, in deference to Gouaux and colleagues and for direct comparison with their work (Armstrong et al., 1998; Armstrong and Gouaux, 2000), we refer to GluRB (i.e., GluR2) residues with respect to the mature protein without the 24 aa signal peptide. Conversion of other GluRs to the mature protein numbering system used by some authors can be obtained by subtracting the following signal peptides lengths: GluRA, 18; GluRC, 22; GluRD, 21; GluR5, 34, and GluR6, 31.

Cell cultures and transfections. Human embryonic kidney 293 (HEK293) fibroblasts (CRL 1573; American Type Culture Collection, Manassas, VA) were cultured in minimal essential medium (MEM) supplemented with $10 \%$ fetal bovine serum and 2 mm GlutaMax (Life Technologies) and incubated at $37^{\circ} \mathrm{C}$ in a $5 \% \mathrm{CO}_{2}$ environment. Cells were plated into $25 \mathrm{~cm}^{2}$ Falcon flasks and passaged twice weekly to fresh flasks. Excess cells were removed, plated into poly-D-lysine-coated $35 \mathrm{~mm}$ Nunc (Naperville, IL) dishes, and cotransfected the following day with cDNA plasmids encoding GluR6 and EGFP at a 9:1 ratio. Cells were transfected using the LipofectaminePLUS reagents (Life Technologies) and incubated for $18-48 \mathrm{hr}$ before use.

Patch-clamp recording. Cells were continuously superfused with standard extracellular solution containing (in $\mathrm{mm}$ ): $150 \mathrm{NaCl}, 3 \mathrm{KCl}, 5$ HEPES, $1 \mathrm{MgCl}_{2}, 1.8 \mathrm{CaCl}_{2}, 10$ glucose, and $0.1 \mathrm{mg} / \mathrm{ml}$ phenol red, $\mathrm{pH}$ 7.3. Recording microelectrodes were fabricated from thin-walled borosilicate glass capillary tubes (TW150F; World Precision Instruments, Sarasota, FL) having resistances of 2-4 M $\Omega$ when filled with an internal solution containing (in mM): $135 \mathrm{CsCl}, 10 \mathrm{CsF}, 10$ HEPES, 5 EGTA, 1 $\mathrm{MgCl}_{2}, 0.5 \mathrm{CaCl}_{2}, \mathrm{pH} 7.2,295 \mathrm{mOsm}$. Outside-out patch recordings were performed in voltage-clamp at a holding potential of $-70 \mathrm{mV}$ using an Axopatch 200B amplifier (Axon Instruments, Foster City, CA). Current signals were filtered at $2-5 \mathrm{kHz}$ with an eight pole Bessel filter (Cygnus Technologies, Watergap, PA), digitized at $20 \mathrm{kHz}$, and stored on a Macintosh PowerPC-G3 computer using an ITC-16 interface (Instrutech, Great Neck, NY) under the control of the data acquisition and analysis program Synapse (Synergy Research, Silver Spring, MD).

Rapid solution exchange. Rapid agonist applications were achieved using an LSS-3100 piezo-translator (Burleigh Instruments, Fishers, NY). Control and agonist solutions were driven simultaneously at a rate of 0.3 $\mathrm{ml} \mathrm{min}{ }^{-1}$ through the two parallel barrels of a theta tube. The membrane patch was positioned in the control stream near the solution interface, and a piezo-translator was used to rapidly move the theta tube $\sim 50 \mu \mathrm{m}$ such that the solution interface moved across the patch. The rate of solution exchange was $\sim 50 \mu \mathrm{sec}$ as determined by the open-tip junction currents measured at the end of each experiment. Desensitization time constants $\left(\tau_{\mathrm{des}}\right)$ were derived from one or two exponential fits as required using a least squares fitting algorithm. Current decays were fit from 75 to $95 \%$ of peak to steady state. Recovery time constants $\left(\tau_{\text {recov }}\right)$ were derived from twin-pulse experiments having pulse durations of $10 \mathrm{msec}$ with an initial interpulse interval of $100 \mathrm{msec}$ and increments of 100,250 , or 500 msec as required. Peak current amplitudes were measured for the test pulses relative to the conditioning pulse, plotted versus the interpulse interval, and fit with a single exponential function. In some cases, the initial 100 msec test pulse was omitted from the fit because of an apparent delay to recovery that was not considered recovery per se or examined further (Bowie and Lange, 2002).

Immunofluorescence staining. HEK293 cells were plated on poly-Dlysine-coated glass coverslips, transfected with wild-type GluR6 (GluR6wt) or mutant receptors, and examined for $36 \mathrm{hr}$ after transfection. Cells were washed twice in $50 \mathrm{~mm}$ Tris-buffered saline (TBS) and fixed in TBS plus $3.7 \%$ formaldehyde. Fixed cells were washed, blocked in TBS plus $2 \%$ normal goat serum (TBSgs), and incubated for $1-3 \mathrm{hr}$ in chick antiN-GluR6 antibody (1:3000) in TBSgs. Cells were then washed three times in TBS, blocked in TBSgs, and incubated with Alexa 488-conjugated secondary goat anti-chick antibodies (1:750). After surface staining, cells were washed three times in TBS, permeabilized in TBS plus $0.1 \%$ Triton $\mathrm{X}-100$, washed, blocked in TBSgs, and incubated for $1-3 \mathrm{hr}$ in rabbit anti-C-GluR6. Cells were then washed three times in TBS, blocked in TBSgs, and incubated with Alexa 568-conjugated secondary goat antichick antibodies (1:750). Immunofluorescence staining was visualized and digitally captured using an OZ confocal laser-scanning microscope (Noran Instruments, Middletown, WI).

Surface biotinylation assays. HEK293 cells were transiently transfected GluR6 wild-type or mutant cDNAs plus EGFP 36-48 before biotinylation. Cells were washed three times in an ice-cold borate buffer and subsequently treated with $0.05 \mu \mathrm{g} / \mathrm{ml}$ EZ-Link sulfo-NHS-SS-biotin (Pierce, Rockford, IL). The reaction was terminated by the removal of reagent and the addition of $15 \mathrm{mM} \mathrm{NH}_{4} \mathrm{Cl}$. Cells were then washed three times with TBS ( $100 \mathrm{~mm} \mathrm{NaCl}, 50 \mathrm{~mm}$ Tris, pH 7.5). Cells were lysed and proteins were solubilized in RIPA buffer [1\% Triton X-100, $1 \%$ sodium deoxycholate, $0.1 \%$ SDS, $150 \mathrm{~mm} \mathrm{NaCl}, 10 \mathrm{~mm}$ sodium phosphate, $2 \mathrm{~mm}$ EDTA, $50 \mathrm{~mm} \mathrm{NaF}, 0.2 \mathrm{~mm}$ sodium vanadate, $0.2 \%$ protease inhibitor mixture (Sigma, St. Louis, MO)] for $1 \mathrm{hr}$ at $4^{\circ} \mathrm{C}$. Samples were centrifuged for $15 \mathrm{~min}$ at $15,000 \times \mathrm{g}$, and supernatant protein concentration was determined by BCA protein assay (Pierce). Solubilized protein (50 $\mu \mathrm{g}$ ) was incubated for $3 \mathrm{hr}$ at $4^{\circ} \mathrm{C}$ with $100 \mu \mathrm{l}$ of washed UltraLink Immobilized NeutrAvidin (Pierce). Biotinylated proteins were pelleted by centrifugation for $5 \mathrm{~min}$ at 7,000 $\times$ g. Pellets were washed twice in RIPA buffer and twice more in TBS. Laemmli sample buffer was added directly to the washed pellets, and proteins were subjected to SDS-PAGE.

Gel electrophoresis and Western blotting. Proteins were electrophoretically separated on 7.5\% polyacrylamide ReadyGels (Bio-Rad Laboratories, Hercules, CA) and electrophoretically transferred to nitrocellulose. Nitrocellulose was blocked with $3 \%$ casein and subsequently incubated for $90 \mathrm{~min}$ with rabbit anti-C-GluR antibodies (1:1000). Blots were washed three times in TBS plus $0.05 \%$ Tween 20 and subsequently probed with goat anti-rabbit alkaline phosphatase (Bio-Rad). Immunoreactive protein was detected using the Immun-Star chemiluminescent system (Bio-Rad), visualized on Hyperfilm ECL (Amersham Biosciences, Buckinghamshire, UK), and quantified by densitometry using NIH ImageJ software (http://rsb.info.nih.gov).

Antibodies and other materials. Reagents were from Sigma or RBISigma (Natick, MA). Chick polyclonal anti-N-GluR6 was raised against the KLH-conjugated peptide fragment SDNKDSFYVSLYPDFSS, corresponding to amino acids $139-155$ in the N-terminal domain of GluR6, and affinity purified against the antigenic peptide (Aves Labs, Tigard, OR). The N-GluR6 antibodies were found to cross-react with cytosolic proteins in HEK293 cells but not with any surface proteins in nontransfected cells. Rabbit polyclonal anti-C-GluR6/7 was from Upstate Biotechnology (Lake Placid, NY). Rabbit polyclonal anti-C-GluRA was from Chemicon (Temecula, CA). Alexa 488- and Alexa 568-conjugated secondary antibodies were from Molecular Probes (Eugene, OR). Alkaline phosphatase-conjugated goat anti-rabbit secondary antibodies were from Bio-Rad. 


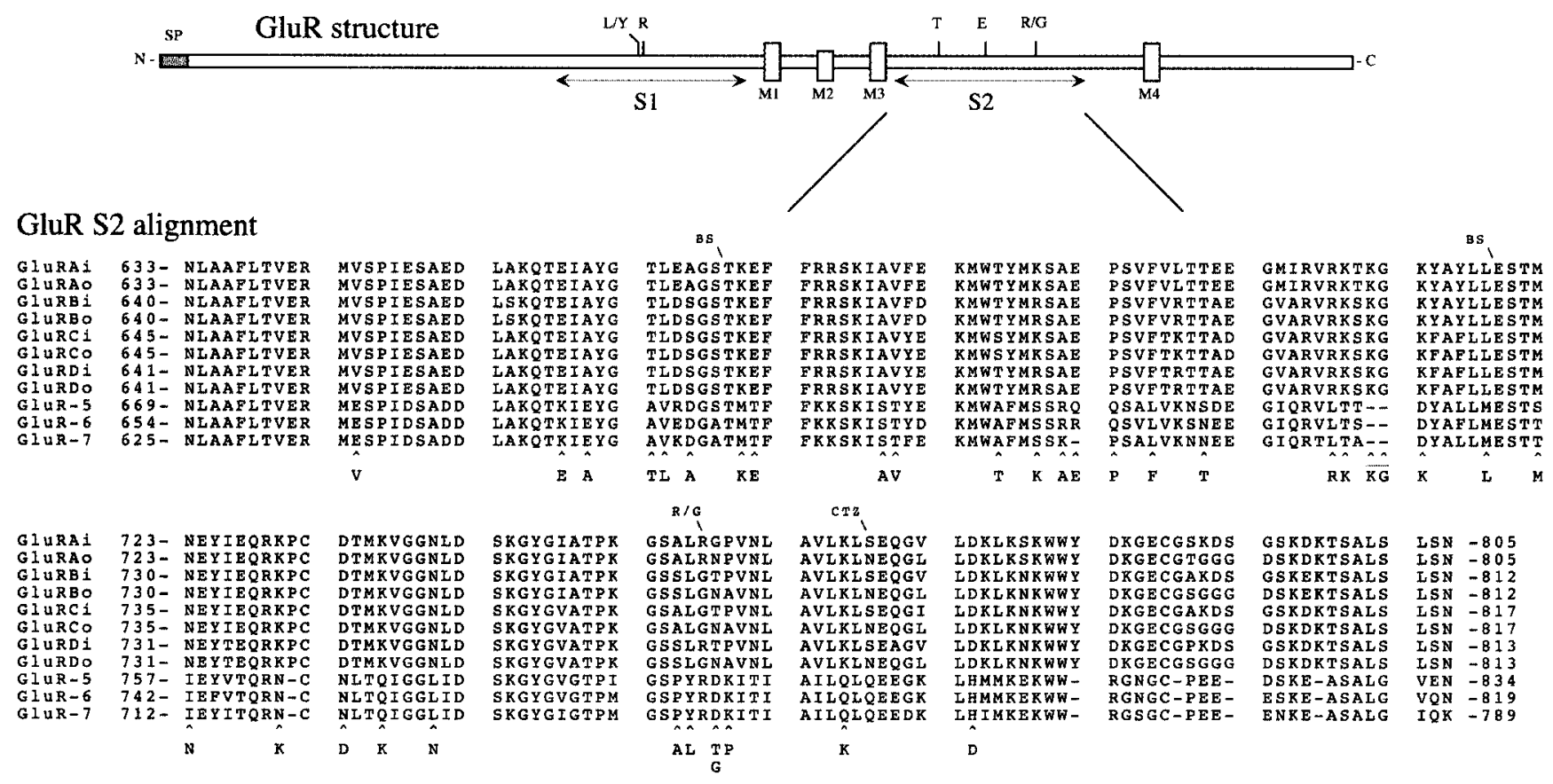

Figure 1. GluR structure and amino acid sequence alignments. Top, Linear structure showing the relative positions of S1 and S2 agonist-binding domains, M1-M4 membrane domains (boxes), and specific amino acid residues involved in ligand binding and function. $L / Y$ denotes the site of the nondesensitizing $L$ to $Y$ mutation (Y521 in GluR6). R/G denotes the mRNA editing site that delineates the border of the AMPA receptor flip (i)/flop (o) domain alternatively spliced domain. Other residues indicated are putative agonist-binding residues R523, T690, and E738 in GluR6. Bottom, Amino acid sequence alignments of the $\$ 2$ segments of GluRA-GluRD (AMPA subunits) and GluR5-GluR7 (KA subunits). AMPA receptor flip (i) and flop (o) isoforms are shown that differ only after the R/G editing site. GluR6 residues were selected for mutagenesis as indicated by arrows below the aligned sequences. BS denotes putative ligand-binding residues T690 and E738. CTZ indicates the $\mathrm{S} / \mathrm{N} / \mathrm{Q}$ site involved in modulation by cyclothiazide.

\section{Results}

\section{GluR6 S2 mutations}

We hypothesized that a compensatory substitution in the GluR6 S2 segment either makes or breaks an interaction with Y521 in the S1 segment and thus preserves desensitization of GluR6, whereas $\mathrm{L}$ to $\mathrm{Y}$ mutations of the equivalent residue in AMPA receptors uniformly prevent desensitization. Our strategy was to identify a single amino acid residue in the S2 domain that differs between AMPA and KA receptor subunits and compensates for the effects of the L/Y substitution on desensitization. Residues in the GluR6 S2 domain that are conserved among AMPA receptor subunits but differ between AMPA and KA receptors were selected for mutagenesis. We chose to ignore very conservative substitutions between aliphatic, aromatic, or like-charged residues; an exception was made for V685(L) because the inverse mutation in AMPA receptors (L646V) was implicated in KA-induced desensitization (Mano et al., 1996). Mutations were designed to substitute various GluR6 residues with the equivalent amino acid present in GluRA or with a consensus amino acid present in other AMPA subunits (Fig. 1). Mutations were scattered throughout the S2 domain but were primarily around and between T690 and E738, residues that are presumed to interact directly with ligand based on the crystal structure of GluR2 (Armstrong et al., 1998; Armstrong and Gouaux, 2000), and around the R/G editing site (R775), which has been shown previously to affect GluR desensitization (Lomeli et al., 1994; Mosbacher et al., 1994). An additional mutation $x 731 \mathrm{KG}$ replaced a gap in the GluR6 sequence that aligns with $\mathrm{KG}$ in all AMPA receptors.

\section{Wild-type GluR6 properties}

Recombinant GluR6-wt receptors were expressed in HEK293 cells and examined by patch-clamp recording. Outside-out patch currents were evoked by fast application of $3 \mathrm{~mm}$ Glu, $300 \mu \mathrm{M} \mathrm{KA}$, or $200 \mu \mathrm{M}$ AMPA, and the time constants for desensitization and recovery from desensitization were determined for the wild-type and S2 mutant receptors (see Materials and Methods); values are given in Table 1 (available at www.jneurosci.org). GluR6-wt responded to Glu and KA, both of which induced a rapidly desensitizing response, but not to AMPA (Fig. $2 A$ ). Peak Glu-evoked currents were $3.6 \pm 0.4 \mathrm{nA}(n=30)$. The time constants for desensitization $\left(\tau_{\text {des }}\right)$ to Glu and KA were $3.0 \pm 0.1 \mathrm{msec}(n=30$; range, $2.0-4.2 \mathrm{msec})$ and $3.3 \pm 0.2 \mathrm{msec}(n=13$; range, $2.4-4.4$ msec), respectively. When tested in the same patches, the peak KA response was $34 \pm 2 \%$ of the peak Glu response $(n=13$; range, 22-46\%); this KA/Glu ratio reflects two factors: (1) 300 $\mu \mathrm{M} \mathrm{KA}$ was $\sim 70 \%$ of saturation $\left(\mathrm{EC}_{50} 145 \mu \mathrm{M}\right)$ whereas $3 \mathrm{~mm}$ Glu was saturating $\left(\mathrm{EC}_{50} 200 \mu \mathrm{M}\right)$, and (2) KA acts as a partial agonist at GluR6-wt receptors producing a maximal response $~ 50 \%$ of that produced by saturating Glu (Fig. $2 B$ ). The rate of recovery from desensitization was determined from twin-pulse experiments with Glu $(3 \mathrm{~mm} \times 10 \mathrm{msec})$ pulses delivered at varying interpulse intervals. The time constant for recovery $\left(\tau_{\text {recov }}\right)$ of GluR6-wt was $1.3 \pm 0.1 \mathrm{sec}(n=10$; range, $0.9-1.8 \mathrm{sec})$.

\section{GluR6 S2 mutant properties}

Similar to GluR6-wt, none of the GluR6 S2 mutants responded to $200 \mu \mathrm{M}$ AMPA except the N721T mutant described previously (Swanson et al., 1997). For N721T, the AMPA-evoked current was $13 \pm 6 \%$ of the Glu current at $200 \mu \mathrm{M}$ AMPA $(n=5)$ or $19 \pm$ $3 \%$ at $1 \mathrm{~mm}$ AMPA $(n=7)$. All but one of the S2 mutations were well tolerated, and most mutations had only moderate, if any, effect on the kinetics of desensitization or recovery from desensitization (Table 1, available at www.jneurosci.org). The only mutation not tolerated was D776T, adjacent to the R/G mRNA 

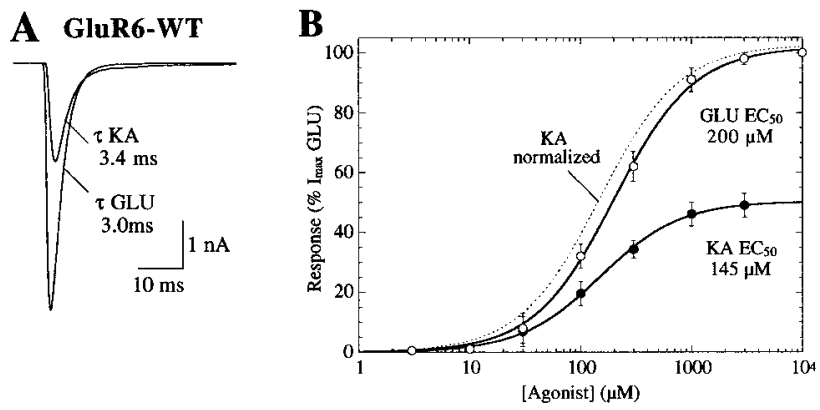

C
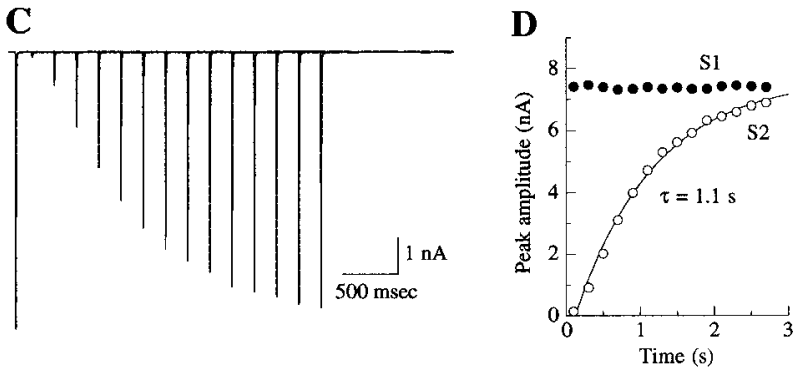

Figure 2. GluR6-wt functional properties. A, Agonist-evoked current responses to $50 \mathrm{msec}$ application of $3 \mathrm{~mm}$ Glu and $300 \mu \mathrm{m}$ KA in the same patch. Transfected HEK293 cells were voltage-clamped to $-70 \mathrm{mV}$. Desensitization time constants $(\tau)$ are given for single exponential fits to the decay in the continued presence of agonist. The ratio of KA/Glu currents is 0.39 in this case or 0.34 on average (see Results). B, Concentration-response curves for KA- and Gluevoked currents of wild-type receptors. Points are mean \pm SEM for 3-12 independent observations normalized to the $3 \mathrm{~mm}$ Glu condition. KA acted as a partial agonist with a maximal current at 3 mm that was $49 \pm 7 \%$ of the maximal Glu current. Agonist $\mathrm{EC}_{50}$ values are given in the figure. $C$, The rate of recovery from desensitization was determined from twin pulses of Glu $(3 \mathrm{~mm} \times 10 \mathrm{msec}$ ) delivered at increasing interpulse intervals. Recovery time constants $(\tau)$ were derived from single exponential fits to the recovery of the second response as shown in $D$, where $\mathrm{S} 1$ is the response to the conditioning stimulus and $\mathrm{S} 2$ is the response to the test stimulus.

editing site (R775). D776T was nonfunctional in all measures of Glu- $(n=15)$, KA- $(n=12)$ or AMPA- $(n=12)$ evoked responses. Therefore, we made an alternate mutation to glycine (D776G) as in GluRA rather than threonine as in all other AMPA receptor flip isoforms. In 11 of 20 patches containing the D776G mutant, Glu evoked small currents $(56 \pm 16 \mathrm{pA}$ ) having greatly accelerated desensitization kinetics nearly five times faster than GluR6-wt. No response was measurable in other patches, possibly because they were too small or too fast to resolve, or in any case for AMPA, whereas KA induced a small response that could be resolved in only three of seven patches tested. Other mutants had faster or slower desensitization outside the range of time constants observed for GluR6-wt ( $\sim 50 \%$ faster or slower than the mean) (Fig. 3). Faster desensitization was observed for D732K and H792D in addition to D776G. Slower desensitization was observed for K679E, V685L, T692E, R713E, M737L, T741M, and Q784K. Other mutations had lesser effects, and Glu- and KAinduced desensitization covaried strongly across all of the S2 mutants tested ( $r=0.91)$ (Fig. $4 A)$.

In general, S2 mutations were found to be more likely to affect recovery from desensitization than desensitization per se, and the effects on recovery were generally greater. Mutations that altered recovery kinetics were scattered throughout the S2 domain, and their effects ranged from a nearly sixfold acceleration to a sixfold slowing of recovery time constants. Notably faster recoveries outside the range seen for GluR6-wt were produced by E681A, D687A, S710R, M737L, T741M, and to a lesser extent by A707T and Y774L mutations. Slower recoveries were seen for V685L, T692E, T701V, N721T, and to a lesser extent for K679E, A684T,
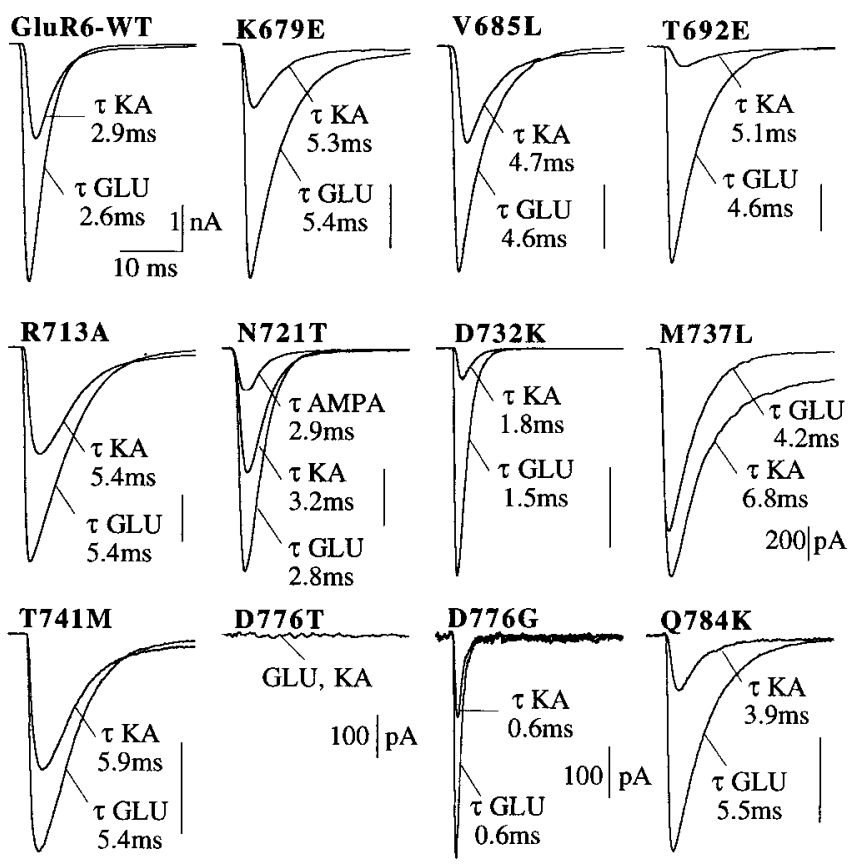

Figure 3. Agonist-evoked currents at GluR6 S2 mutant receptors. Transfected HEK293 cells were voltage-clamped to $-70 \mathrm{mV}$ and tested by ultrafast application of $3 \mathrm{~mm}$ Glu and $300 \mu \mathrm{m}$ $K A$ in the same patches. Desensitization time constants $(\tau)$ are given for single exponential fits to the decay in the continued presence of agonist. AMPA-evoked current trace is shown only for N721T, because other mutants did not respond to AMPA. Note also that the ratio of KA/Glu currents varies considerably in some cases (Table 1, available at www.jneurosci.org). Calibration: $1 \mathrm{nA}$ (for all traces except as indicated for D776T/G and M737L), $10 \mathrm{msec}$.
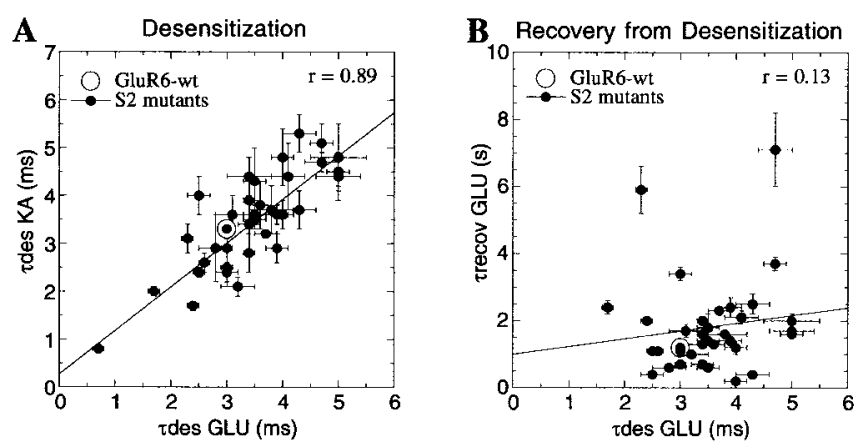

Figure 4. Kinetics of Glu- and KA-induced desensitization are strongly correlated. A, Desensitization time constants $(\tau)$ are plotted for all GluR6 S2 mutants and fit with a linear regression having a slope of 0.91 and a correlation coefficient $(r)$ of 0.89 . $B$, No consistent relationship was observed between the kinetics of Glu-induced desensitization and recovery from desensitization (slope $=0.23 ; r=0.13$ ). Data points in $A$ and $B$ are mean \pm SEM for $3-30$ independent observations per mutant.

D732K, N749K, Q754K, L758N, and H792D. There was no consistent relationship between desensitization and recovery time constants across all of the mutants tested in this study $(r=0.13)$ (Fig. $4 B$ ). We note that recoveries were generally well fit by a single exponential excluding the earliest time points, and similar results were obtained from measures of the T1/2 (time for 50\% recovery) which makes no assumption about the underlying kinetic processes.

Aside from N721T, other S2 domain mutations did not produce AMPA-sensitive receptors. Nonetheless, effects of some mutations on agonist binding or gating were apparent from the relative amplitudes of KA- and Glu-evoked currents. Several mu- 
tants had increased KA/Glu ratios reflecting a preferential reduction in Glu-evoked currents. Most notably, the KA/Glu ratio was increased more than fourfold for the M737L mutant, apparently reflecting a preferential reduction in the peak Glu-evoked current by $73 \%$ compared with GluR6-wt. Likewise for T741M, the KA/ Glu ratio increased twofold, consistent with an observed $47 \%$ reduction in Glu-evoked currents, and the 50\% higher KA/Glu ratio for $\mathrm{V} 685 \mathrm{~L}$ was consistent with a $21 \%$ reduction in peak Glu-evoked currents compared with GluR6-wt. Other mutants had reduced KA/Glu ratios, reflecting a preferential reduction in KA-evoked currents. The mutant Q754K showed no reduction in Glu-evoked currents compared with GluR6-wt, but a 48\% reduction in KA-evoked currents, and KA/Glu was reduced to 0.2 versus 0.34 for GluR6-wt. The mutants T692E, T701V, D732K, and $\mathrm{H} 792 \mathrm{D}$ had reduced $\mathrm{KA} / \mathrm{Glu}$ ratios in the range of $0.08-0.12$, but these reflected both reductions in Glu-evoked currents (by 42, 40, 62 and 56\% vs GluR6-wt, respectively) and greater reductions in KA-evoked currents (by 80, 83, 92, and 87\%, respectively). Thus, all mutants having a higher KA/Glu ratio had preferentially reduced Glu-evoked currents, and all mutants having a lower KA/ Glu ratio had preferentially reduced KA-evoked currents, usually accompanied by a smaller effect on Glu-evoked currents. Studies are ongoing to assess whether altered KA/Glu ratios reflect differences in expression, ligand binding, gating, or desensitization; note that some mutants having altered KA/Glu ratios had altered $\tau_{\text {des }}$ KA or $\tau_{\text {des }}$ Glu, whereas others did not.

Considering the effects of exchanges between residues 732 741 on agonist gating and desensitization, we suspected the gap in the sequence alignments at 731 might contribute to the differences between AMPA and KA receptor desensitization (Fig. 1). To test this, we generated the mutant $\mathrm{x} 731 \mathrm{KG}$, inserting two amino acids (lysine, glycine) between residues 731 and 732 in GluR6. This insertion had little effect on KA- or Glu-evoked responses, and the mutant behaved essentially like GluR6-wt by all measures (Table 1, available at www.jneurosci.org).

\section{Dimerization mutants}

We subsequently examined why D776T and D776G, among all of the other S2 mutations tested, had such deleterious effects on receptor function. Some insight was provided by the crystal structure of GluR2 S1S2 binding protein, in which the equivalent residue, N744 in GluR2flop, resides at the interface between GluR2 S1S2 protein dimers (Armstrong and Gouaux, 2000). Perhaps then, D776 makes essential interactions between binding sites of GluR6 dimers that serve to stabilize the dimeric conformation of the agonist-binding site and also to influence channel gating or desensitizing properties. To test this idea, we made mutations of other residues predicted to lie along the dimer interface in both the S1 and S2 domains. Based on examination of the GluR2 dimer crystal structure (Armstrong and Gouaux, 2000), E486 in one GluR2 subunit was found to interact by hydrogen bonding with K493 and N747 of its partner GluR2 subunit in a reciprocal, antiparallel configuration (Fig. 5). Our mutagenesis strategy was to neutralize these residues individually by substitution to glycine, thus neutralizing their side-chain interactions with one another, and then to examine the functional properties of the mutant receptors. The equivalent residues in GluR6 are E524, K531, and T779; thus we produced the corresponding dimerization mutants E524G, K531G, and T779G in addition to D776G.

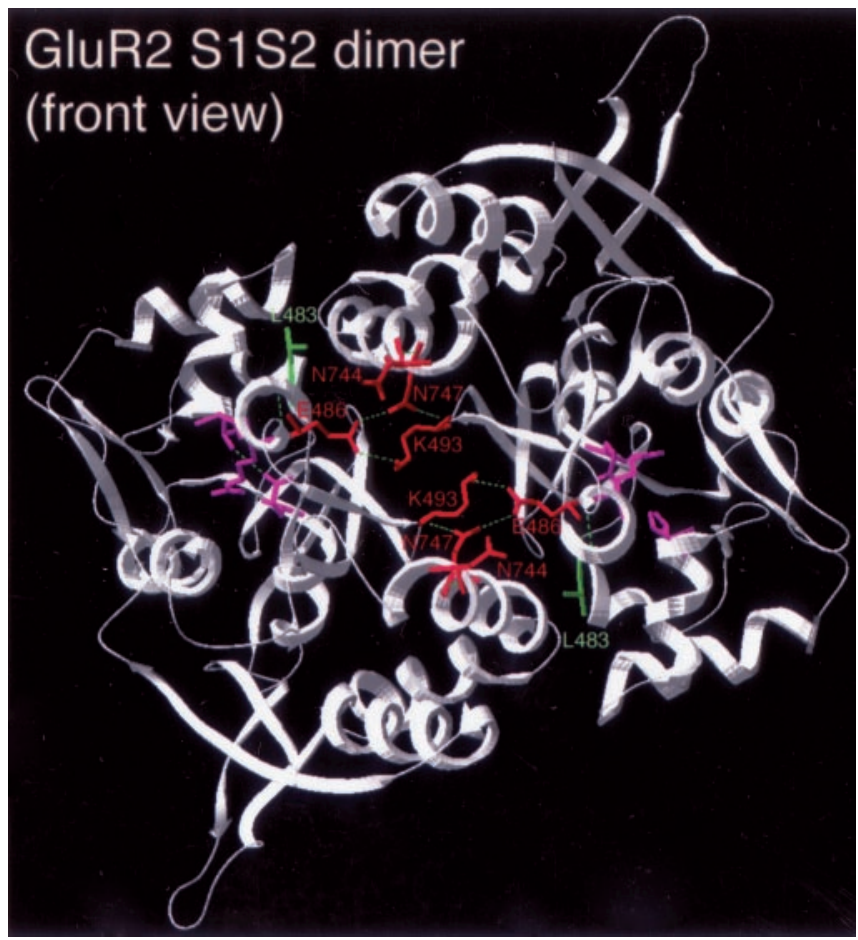

Figure 5. Dimeric structure of GluR2 S1S2 crystals. A front view of S1S2 dimers from Armstrong and Gouaux (2000) is shown (PDB 1FT0). Dimerization residues are shown in red, ligandbinding residues are shown in magenta, and the $L / Y$ residue is shown in green. Hydrogen bonds are indicated by dashed lines in green showing reciprocal interactions between residue E486 (S1) of one subunit and K493 (S1) and N747 (S2) of its partner subunit. The equivalent residues in GluR6 are E524, K531, and T779, respectively. The N744 residue is equivalent to D776 in GluR6. Putative ligand-binding residues R485, T655, and E705 (magenta) are equivalent to $\mathrm{R} 523, \mathrm{~T} 690$, and $\mathrm{E738}$ in GluR6, and the L/Y residue L483 ( green) is equivalent to Y521 in GluR6.

A $2524 G$

GLU, KA

$$
\frac{100 / \mathrm{pA}}{10 \mathrm{~ms}}
$$

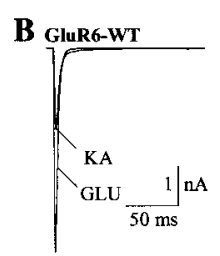

Figure 6. Agonist-evoked currents at GluR6 putative dimerization mutant receptors are shown. Transfected HEK293 cells were voltage-clamped to $-70 \mathrm{mV}$ and tested by ultrafast application of $3 \mathrm{~mm}$ Glu and $300 \mu \mathrm{m} \mathrm{KA}$ in the same patches. Note that the ratio of KA/Glu currents is $\sim 1$ in most cases, suggesting that both are full (or equivalent partial) agonists. $A$, Current responses are plotted on $50 \mathrm{msec}$ time scale as in previous figures. $B$, Current responses are plotted on $250 \mathrm{msec}$ time scale to demonstrate the biphasic fast and slow kinetics of deactivation after the removal of agonists and the large steady-state currents evoked by KA and to a lesser extent by Glu at receptors bearing the $K 531 \mathrm{G}$ mutation.

\section{Dimerization mutant properties}

Homomeric GluR6 mutant receptors were expressed in HEK293 cells and tested by outside-out patch-clamp recording in response to Glu $(3 \mathrm{mM})$ or $\mathrm{KA}(300 \mu \mathrm{M})$ in many of the same patches. Representative current traces are shown in Figure 6, with a summary of kinetic data given in Table 2 . The only mutation in this series not tolerated was E524G, adjacent to the presumed 
Table 2. Agonist-evoked currents and desensitization kinetics of GluR6 putative dimerization mutants

\begin{tabular}{|c|c|c|c|c|c|c|c|c|c|c|c|}
\hline \multirow[b]{2}{*}{ Mutant } & \multicolumn{5}{|l|}{3 mm Glutamate } & \multicolumn{6}{|l|}{$300 \mu \mathrm{m}$ Kainate } \\
\hline & $\tau_{\text {des }}$ Fast (msec) & $\%$ Fast & $\tau_{\text {des }}$ Slow (msec) & Iss (\%) & $n$ & $\tau_{\text {des }}$ Fast (msec) & $\%$ Fast & $\tau_{\text {des }}$ Slow (msec) & Iss (\%) & KA/Glu Peak (\%) & $n$ \\
\hline R6-WT & $3.0 \pm 0.1$ & 100 & NA & NA & 10 & $3.3 \pm 0.2$ & 100 & NA & NA & $34 \pm 2$ & 13 \\
\hline E524G & NA & NA & NA & NA & 5 & NA & NA & NA & NA & NA & 5 \\
\hline K531G & $3.5 \pm 0.2$ & $55 \pm 4$ & $18 \pm 2$ & $16 \pm 2$ & 15 & NA & NA & $19 \pm 1$ & $77 \pm 3$ & $137 \pm 32$ & 9 \\
\hline D776G & $0.7 \pm 0.1$ & 100 & NA & NA & 11 & $0.8 \pm 0.1$ & 100 & NA & NA & $35 \pm 4$ & 3 \\
\hline T779G & $0.5 \pm 0.1$ & $89 \pm 2$ & $4.6 \pm 0.9$ & $3 \pm 1$ & 7 & $4.0 \pm 0.7$ & $48 \pm 3$ & $42 \pm 6$ & $25 \pm 3$ & $171 \pm 26$ & 114 \\
\hline K531G/T779G & $4.8 \pm 0.8$ & $48 \pm 7$ & $28 \pm 4$ & $21 \pm 3$ & 5 & NA & NA & $21 \pm 4$ & $88 \pm 2$ & $97 \pm 7$ & 3 \\
\hline
\end{tabular}

Values are mean \pm SEM. NA, Not observed; Iss, steady-state current as a percentage of peak.

ligand-binding residue R523 in the S1 segment. Like the D776T mutant described above, E524G was nonfunctional in all measures of Glu- $(n=12)$ and KA- $(n=8)$ evoked responses; E524G also failed to respond to $30 \mathrm{~mm}$ Glu $(n=3)$. The other presumed dimerization mutants also had dramatically altered functional properties. The K531G mutant desensitized more slowly than GluR6-wt and desensitized only partially; steady-state currents were $16 \pm 2 \%$ of peak for Glu and $77 \pm 3 \%$ of peak for KA (Table 2, Fig. 6). In addition, the ratio of KA/Glu currents was increased to $1.4 \pm 0.3$ such that KA was more effective than Glu in addition to being less desensitizing. Also striking was the biphasic nature of K531G deactivation after the removal of KA. GluR6-wt deactivation followed a single exponential function having a time constant $\left(\tau_{\text {deact }}\right)$ of $1.8 \pm 0.4 \mathrm{msec}(n=8)$, whereas deactivation of K531G had both fast $\left(\tau_{\mathrm{f}} 0.4 \pm 0.1 \mathrm{msec}\right)$ and slow $\left(\tau_{\mathrm{s}} 62 \pm 10\right.$ msec) components representing 23 and $77 \%$, respectively, of the current decay. The T779 G mutant desensitized more rapidly than GluR6-wt in response to Glu but more slowly in response to KA (Table 2, Fig. 6). Steady-state currents were measurable for both agonists, albeit smaller than those expressed by $\mathrm{K} 531 \mathrm{G}$, and the ratio of KA/Glu peak currents was increased compared with GluR6-wt (to $1.7 \pm 0.3 ; n=4$ ), apparently reflecting a reduction in Glu-evoked currents. Like K531G, the T779G mutant displayed both fast $\left(\tau_{\mathrm{f}} 0.7 \pm 0.1 \mathrm{msec}\right)$ and slow $\left(\tau_{\mathrm{s}} 68 \pm 5 \mathrm{msec}\right)$ deactivation after the removal of KA representing 54 and $46 \%$, respectively, of the current decay. Because the E524 residue is thought to interact with both K531 and T779, we tested whether neutralizing both of these residues might reproduce the gating defect seen with E524G. It did not. Rather, the double mutant K531G-T779G behaved in all respects much like the K531G mutant (Table 2, Fig. 6).

Finally, we sought to determine the nature of the nonfunctional defects produced by the E524G and D776T mutations. Immunofluorescence staining and surface biotinylation assays confirmed the expression of E524G, K531G, and T779G mutant GluRs on the cell surface, although D776T and D776G surface expression was considerably weaker (Fig. $7 A, B$ ). Surprisingly, two GluRA equivalent mutants, E500G and K507G, could not be detected on the cell surface (Fig. 7C). We also tested E524G and D776T by whole-cell recording before and after treatment with concanavalin A to determine whether these mutations produced a defect in channel gating or accelerated desensitization such that currents could not be resolved (Fig. 8). In the whole-cell configuration, small Glu-evoked currents could be resolved for E524G having an amplitude of $26 \pm 14 \mathrm{pA}$, and these were increased to $2.4 \pm 0.4 \mathrm{nA}(n=5)$ after treatment for $20 \mathrm{sec}$ with $0.3 \mathrm{mg} / \mathrm{ml}$ concanavalin A. Likewise, small KA-evoked currents could be resolved, which were increased from $41 \pm 27 \mathrm{pA}$ to $3.4 \pm 1.0 \mathrm{nA}$ $(n=4)$ after treatment with concanavalin A. Similar results were obtained for D776T, although the current amplitudes were considerably smaller, reflecting their poor surface expression; Glu-

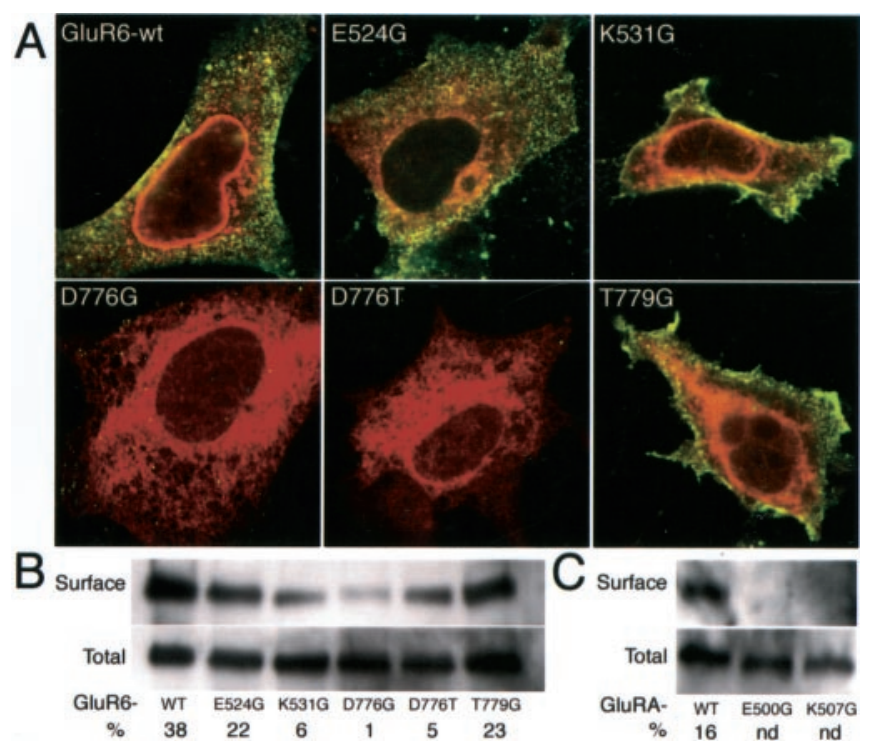

Figure 7. Surface expression of GluR6-wt and putative dimerization mutants. A, Confocal images of immunofluorescence staining with anti-GluR6 antibodies raised against extracellular $\mathrm{N}$-terminal and intracellular C-terminal peptide fragments. N-GluR6 staining of intact cells ( green) showed robust expression of GluR6-wt on the cell surface in 30-70\% of cells reflecting the transfection efficiency; the same cells were positive for C-GluR6 staining after permeabilization (red). Similar profiles were seen for E524G, K531G, and T779G, whereas D776T and D776G stained poorly on the cell surface; note the reticular appearance of D776T and D776G suggesting that they are retained in the ER. Controls for staining of nontransfected cells or without primary antibodies were uniformly negative. $B, C$, Western blots of $C$-GluR6 staining of GluR6-wt and mutant receptors $(B)$ or C-GluRA staining of GluRA-wt and mutant receptors $(C)$ in the biotinylated surface and total protein fractions; lanes represent $10 \mu \mathrm{g}$ of total protein homogenate (Total) versus $50 \mu \mathrm{g}$ of NeutrAvidin precipitated proteins (Surface). Relative surface expression (\%) is given below the blots, which confirmed the reductions seen by immunofluorescence staining for the D776T and D776G mutant receptors. nd, Not detected.

evoked currents were increased from $12 \pm 4$ to $205 \pm 37 \mathrm{pA}$ ( $n=$ 5 ), and KA-evoked currents were increased from $22 \pm 16$ to $457 \pm 101 \mathrm{pA}$ after treatment with concanavalin A. These data indicate that the E524G and D776T mutants are not gating deficient but desensitize too quickly to be resolved or may be tonically desensitized, because the defects can be reversed by block of desensitization with concanavalin A. In contrast, we could not resolve any whole-cell Glu-evoked currents for the GluRA mutants E500G or K507G in the absence or presence of $100 \mu \mathrm{M}$ cyclothiazide, consistent with their more profound disruption of surface labeling in biotinylation assays.

\section{Discussion}

\section{S1S2 domain interactions}

The discovery of the L/Y site in AMPA receptors (Stern-Bach et al., 1994, 1998) accelerated our understanding of GluR desensitization. Yet the equivalent substitution does not prevent KA receptor desensitization. Indeed, KA receptors naturally harbor a 

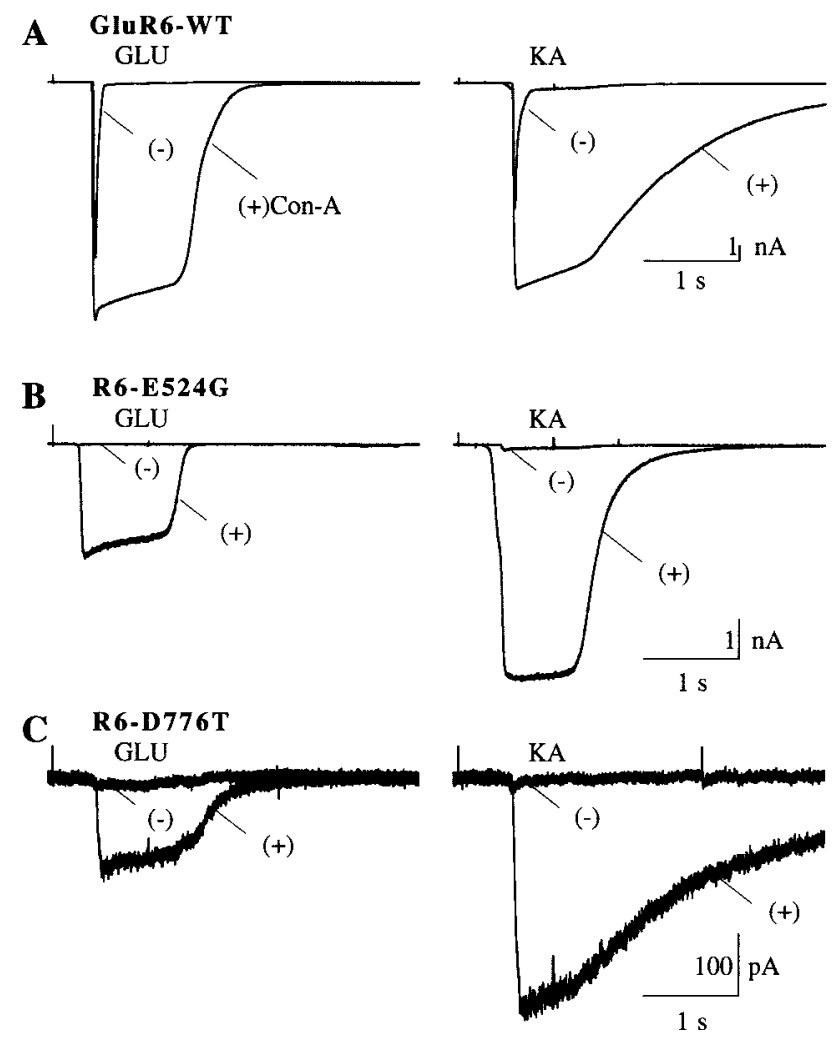

Figure 8. Rescue of nonfunctional GluR6 mutants by concanavalin A. Transfected HEK293 cells were voltage-clamped to $-70 \mathrm{mV}$ in the whole-cell configuration and tested by fast application of $3 \mathrm{~mm}$ Glu and $300 \mu \mathrm{M} \mathrm{KA}$ in the same cells. $A$, Pretreatment for $30 \mathrm{sec}$ with concanavalin A (Con-A) blocked desensitization of GluR6-wt receptors induced by Glu or KA. B, C, Small agonist-evoked whole-cell currents were observed for the E524G and D776T mutant receptors that could not be resolved in outside-out patch recording (Fig. 6), and these currents were enhanced greatly after pretreatment with Con A. The relatively smaller D776T currents are consistent with the reduced surface expression of this mutant (Fig. 7).

tyrosine residue in the equivalent position (Y521 in GluR6). The reason for this difference between the molecular mechanisms of AMPA and KA receptor desensitization, despite all their structural and functional similarities, has since remained unclear. The present study provides no solution but does suggest that the difference is not a simple interaction between Y521 and a single S2 residue. Not all S2 residues were examined, however, and the possibility remains that multiple residues are required to support such an interaction with residue Y521. More likely, we believe that additional structural constraints in GluR6 support unique interactions not predicted from linear sequence alignments (e.g., D776T/G mutants).

\section{Effects of S2 mutations}

Various mutations throughout the GluR6 S2 segment had effects on KA- and Glu-evoked currents, desensitization, or recovery from desensitization. The most active mutations were near putative agonist-binding residues, but even these had only modest effects on the kinetics of desensitization. The residue having the single greatest effect on GluR6 function was found adjacent to the R/G editing site (R775), because mutations of D776 greatly accelerated the process of desensitization and reduced functional expression on the cell surface. Other residues were found scattered throughout S2 that were less critical and seemed more likely to influence the resistance of S2 to the conformational changes as- sociated with channel gating or desensitization rather than having any direct role in these processes.

The present study did not identify a single residue in the S2 segment that permits KA to desensitize KA receptors while producing a nondesensitizing current in AMPA receptors (Kiskin et al., 1986; Patneau and Mayer, 1991; but see Patneau et al., 1993). Notably, mutation of the V685 residue (V685L), identified in GluRA (L646V) (Mano et al., 1996) as being critical for KAinduced desensitization, slowed but did not prevent desensitization to KA in GluR6. Nearby mutations A689S (Swanson et al., 1997) and T692E (Fig. 3, Table 1, available at www.jneurosci.org) slowed desensitization to KA and to Glu, and overall we observed a strong correlation between Glu- and KA-desensitization kinetics across all of the S2 mutants tested. These results suggest that the contributions of S2 residues to desensitization are generally not agonist dependent. Importantly, the K531G (S1) mutation nearly abolished KA-induced desensitization (Fig. 6), but this residue is conserved among AMPA and KA subunits and so cannot account for the different actions of KA.

The present study also did not identify any single S2 domain residue in GluR6 that accounts for their $>10$-fold slower recovery from desensitization relative to AMPA receptors. Our data suggest instead that recovery from desensitization is a distributed process involving many S2 residues, possibly other domains as well, but principally involving residues coupled to the ligandbinding site (e.g., E681, V685, N721, M737, T741) and around the R/G editing site (e.g., Y774L). Nonetheless, the fastest GluR6 mutants tested approached the recovery kinetics of GluRA ( $\tau_{\text {recov }}$ $\sim 140 \mathrm{msec}$ ) (Partin et al., 1996), and it remains to be seen whether the combined substitutions of E681A, M737L, and T741M, each of which alone accelerated recovery by more than threefold, could reproduce the fast recovery of AMPA receptors. Interestingly, mutations that altered recovery kinetics did not necessarily alter desensitization itself, and overall we found no relationship between desensitization and recovery kinetics in the S2 mutants tested, consistent with the idea that desensitization and recovery are independent processes.

\section{GluR6 trafficking}

Another interesting albeit unexpected finding was the poor surface expression of D776T and D776G mutants. Western blots and immunofluorescence staining confirmed that the D776 mutants were expressed as full-length GluRs sequestered in the endoplasmic reticulum (ER). The poor surface expression of the D776 mutants was confirmed by N-terminal staining in intact cells, by surface protein biotinylation assays, and by functional studies after concanavalin A treatment. The reason for the inability of D776 mutants to traffic to the cell surface remains unclear. It seems unlikely that these mutations introduced a structural defect, because the mutations substituted the AMPA receptor equivalent residues, and because the few receptors reaching the cell surface were competent. Alternatively, their poor surface expression might be related to a functional checkpoint in ER export. A similar trafficking defect was reported for GluR2 subunits edited at the Q/R site (Greger et al., 2002), and we have found that null mutations of dimerization residues in GluRA (E500G and $\mathrm{K} 507 \mathrm{G}$ ) and of putative ligand-binding residues in GluR6 (R523G, T690G, and E738G, but not E738D) are also retained intracellularly (our unpublished observations). Studies are ongoing to explore further the nature and cause of these GluR trafficking errors. 


\section{Binding-site dimerization}

Recent studies suggest that desensitization is not an intrinsic property of the individual GluR subunits but involves intermolecular interactions between dimerized subunits in the multimeric receptor. Armstrong and Gouaux (2000) found that GluR2 S1S2 (binding site) proteins form dimers in the absence of ligand (Fig. 5). The dimers are stabilized by intersubunit hydrogen bonds between E486, K493, and N747, which are lost on agonist binding but retained on agonist binding in the presence of cyclothiazide or in the agonist-bound L/Y mutant form of GluR2 S1S2 (Sun et al., 2002). A consensus has begun to emerge that GluRs are probably tetramers (Laube et al., 1998; Mano and Teichberg, 1998; Rosenmund et al., 1998; but see Ferrer-Montiel and Montal, 1996; Premkumar and Auerbach, 1997) assembled as dimers of dimers (Mansour et al., 2001; Robert et al., 2001) like $\mathrm{K}^{+}$channels (McKinnon, 1991; Tu and Deutsch, 1999) and cyclic nucleotide-gated channels (Liu et al., 1998). With respect to AMPA receptors, desensitization involves a rearrangement of the dimer interface that uncouples the agonist-binding site from the channel gate (Sun et al., 2002). Support for this idea has come from biophysical studies examining heteromeric channels composed of wild-type and L/Y mutant AMPA receptors (Mansour et al., 2001; Robert et al., 2001) and from biochemical studies demonstrating that GluR2 S1S2 dimerization involves specific residues implicated in desensitization (Sun et al., 2002), including the $\mathrm{L} / \mathrm{Y}$ residue in the $\mathrm{S} 1$ segment and the S/N/Q site of cyclothiazide action (Partin et al., 1994, 1996). Thus, Sun et al. (2002) proposed that desensitization results from breaking dimeric contacts between adjacent binding sites.

\section{GluR6 dimerization and desensitization}

To date, the equivalent crystal structure of the KA receptor binding site has not been resolved; neither has their propensity to form dimers between adjacent binding sites been confirmed. This caveat makes any structural interpretation of KA receptor mutants somewhat problematic. It seems likely by homology that KA receptors, like AMPA receptors, should operate as dimers of dimers, and that residues interacting across the dimer interface might likewise be involved in desensitization. However, a recent comparison of GluRA and GluR6 kinetics suggests that a greater number of conformational steps occur between KA receptor desensitization and recovery, and computational models seem to favor a tetrameric arrangement for KA receptors versus a dimerdimer arrangement for AMPA receptors (Bowie and Lange, 2002). Likewise, other studies suggest stoichiometric differences in AMPA and KA receptor gating (Rosenmund et al., 1998; Smith and Howe, 2000; but see Swanson et al., 2002). Our studies provide new insights into the similarities and differences between AMPA and KA subunits. On the one hand, the dimer interface residues identified in GluR2 S1S2, which are largely conserved among AMPA and KA subunits, also play a role in KA receptor gating and desensitization. Mutations to GluR6 residues E524, K531, and T779, equivalent to GluR2 E486, K493, and N747, had dramatic effects on desensitization, more so than any other S2 mutations examined. Most likely these result from altered intersubunit contacts between dimerized binding sites in the GluR6 homotetramer. On the other hand, the nature of these interactions was different between AMPA and KA subunits. Mutations to GluR6 residue D776, which is perfectly conserved among KA subunits, greatly enhanced desensitization, whereas the equivalent residue in AMPA receptors is neither conserved nor apparently involved in dimerization or desensitization. The GluR6K531G mutant desensitized more slowly than wild-type, whereas the AMPA receptor model predicts that this mutation should disrupt dimerization and promote desensitization; the equivalent GluRA-K507G mutant was not expressed on the cell surface. Likewise, the GluR6-E524G mutant was tonically desensitized, whereas the equivalent GluRA-E500G mutant was not expressed on the cell surface. These residues may therefore contribute to the functional and stoichiometric differences identified in AMPA and KA receptors.

In summary, we have identified specific residues within the GluR6 S2 domain, but more significantly at the putative dimer interface, that contribute to the functional differences between GluR subtypes. Our results are consistent with a close but imperfect structural homology between AMPA and KA receptors and support the role of specific S1S2 interactions, including intersubunit interactions at the dimer interface, in GluR channel function. Ultimately, a more accurate structural interpretation from these and other comparative studies of AMPA/KA receptor function will be aided by atomic-level resolution of the crystal structure of the KA receptor ligand-binding domain.

\section{References}

Abele R, Keinanen K, Madden DR (2000) Agonist-induced isomerization in a glutamate receptor ligand-binding domain. J Biol Chem 275:21355-21363.

Armstrong N, Gouaux E (2000) Mechanisms for activation and antagonism of an AMPA-sensitive glutamate receptor: crystal structures of the GluR2 ligand binding core. Neuron 28:165-181.

Armstrong N, Sun Y, Chen G-Q, Gouaux E (1998) Structure of a glutamatereceptor ligand-binding core in complex with kainate. Nature 395:913-917.

Bettler B, Boulter J, Hermans-Borgmeyer I, O'Shea-Greenfield A, Deneris ES, Moll C, Borgmeyer M, Hollman M, Heinemann S (1990) Cloning of a novel glutamate receptor subunit, GluR5: expression in the nervous system during development. Neuron 5:583-595.

Boulter J, Hollmann M, O'Shea-Greenfield A, Hartley M, Deneris E, Maron C, Heinemann S (1990) Molecular cloning and functional expression of glutamate receptor genes. Science 249:1033-1037.

Bowie D (2002) External anions and cations distinguish between AMPA and KA receptor gating mechanisms. J Physiol (Lond) 539:725-733.

Bowie D, Lange GD (2002) Functional stoichiometry of glutamate receptor desensitization. J Neurosci 22:3392-3403.

Dingledine R, Borges K, Bowie D, Traynelis SF (1999) The glutamate receptor ion channels. Pharmacol Rev 51:7-61.

Egebjerg J, Bettler R, Hermans-Borgmyer I, Heinemann S (1991) Coning of a cDNA for a glutamate receptor subunit activated by kainate but not AMPA. Nature 351:745-748.

Ferrer-Montiel AV, Montal M (1996) Pentameric subunit stoichiometry of a neuronal glutamate receptor. Proc Natl Acad Sci USA 93:2741-2744.

Greger IH, Khatri L, Ziff EB (2002) RNA editing at Arg607 controls AMPA receptor exit from the endoplasmic reticulum. Neuron 34:759-772.

Heckmann M, Bufler J, Franke C, Dudel J (1996) Kinetics of homomeric GluR6 glutamate receptor channels. Biophys J 71:1743-1750.

Herb A, Burnashev N, Werner P, Sakmann B, Wisden W, Seeburg PH (1992) The KA-2 subunit of excitatory amino acid receptors shows widespread expression in brain and forms ion channels with distantly related subunits. Neuron 8:775-785.

Hollmann M, Heinemann S (1994) Cloned glutamate receptors. Annu Rev Neurosci 17:31-108.

Keinanen W, Wisden W, Sommer B, Werner P, Herb A, Verdoorn TA, Sakmann B, Seeburg PH (1990) A family of AMPA-selective glutamate receptors. Science 249:556-560.

Kiskin NI, Krishtal OA, Tsyndrenko AY (1986) Excitatory amino acid receptors in hippocampus: kainate fails to desensitize them. Neurosci Lett 63:225-230.

Kuryatov A, Laube B, Betz H, Kuhse J (1994) Mutational analysis of the glycine-binding site of the NMDA receptor: structural similarity with bacterial amino acid-binding proteins. Neuron 12:1291-1300.

Kuusinen A, Arvola M, Keinanen K (1995) Molecular dissection of the agonist binding site of an AMPA receptor. EMBO J 14:6327-6332.

Lampinen M, Pentikainen O, Johnson MS, Keinanen K (1998) AMPA receptors and bacterial periplasmic amino acid-binding proteins share the ionic mechanism of ligand recognition. EMBO J 17:4704-4711. 
Laube B, Kuhse J, Betz H (1998) Evidence for a tetrameric structure of recombinant NMDA receptors. J Neurosci 18:2954-2961.

Lerma J, Paternain AV, Rodriguez-Moreno A, Lopez-Garcia JC (2001) Molecular physiology of kainate receptors. Physiol Rev 81:971-998.

Liu DT, Tibbs GR, Paoletti P, Siegelbaum SA (1998) Constraining ligandbinding site stoichiometry suggests that a cyclic nucleotide-gated channel is composed of two functional dimers. Neuron 21:235-248.

Lomeli H, Wisden W, Kohler M, Keinanen K, Sommer B, Seeburg PH (1992) High-affinity kainate and domoate receptors in rat brain. FEBS Lett 307:139-143.

Lomeli H, Mosbacher J, Melcher T, Hoger T, Geiger JRP, Kuner T, Monyer H, Higuchi M, Bach A, Seeburg PH (1994) Control of kinetic properties of AMPA receptor channels by nuclear RNA editing. Science 266:1709-1713.

Mano I, Teichberg VI (1998) A tetrameric subunit stoichiometry for a glutamate receptor-channel complex. NeuroReport 9:327-331.

Mano I, Lamed Y, Teichberg VI (1996) A venus flytrap mechanism for activation and desensitization of $\alpha$-amino-3-hydroxy-5-methyl-4-isoxazolepropionic acid receptors. J Biol Chem 27:15299-15302.

Mansour M, Nagarajan N, Nehring RB, Clements JD, Rosenmund C (2001) Heteromeric AMPA receptors assemble with a preferred subunit stoichiometry and spatial arrangement. Neuron 32:841-853.

McKinnon R (1991) Determination of the subunit stoichiometry of a voltage-activated potassium channel. Nature 350:232-235.

Mosbacher J, Schoepfer R, Monyer H, Burnashev N, Seeburg PH, Ruppersberg JP (1994) A molecular determinant for submillisecond desensitization in glutamate receptors. Science 266:1059-1061.

Oh BH, Pandit J, Kang CH, Nikaido K, Gokcen S, Ames GF, Kim SH (1993) Three-dimensional structures of the periplasmic lysine/arginine/ornithinebinding protein with and without a ligand. J Biol Chem 268:11348-11355.

O'Hara PH, Sheppard PO, Thogersen H, Venezia D, Haldeman BA, McGrane V, Houamed KM, Thomsen C, Gilbert T, Mulvihill ER (1993) The ligand-binding domain in metabotropic glutamate receptors is related to bacterial periplasmic binding proteins. Neuron 11:41-52.

Paas Y, Eisenstein M, Medevielle F, Teihbert VI, Devillers-Thiery A (1996) Identification of the amino acid subsets accounting for the ligand binding specificity of a glutamate receptor. Neuron 17:979-990.

Partin KM, Patneau DK, Winters CA, Mayer ML, Buonanno A (1993) Selective modulation of desensitization at AMPA versus kainate receptors by cyclothiazide and concanavalin A. Neuron 11:1069-1082.

Partin KM, Patneau DK, Mayer ML (1994) Cyclothiazide differentially modulates desensitization of $\alpha$-amino-3-hydroxy-5-methyl-4-isoxazolepropronic acid receptor splice variants. Mol Pharmacol 46:129-138.

Partin KM, Fleck MW, Mayer ML (1996) AMPA receptor flip/flop mutants affecting deactivation, desensitization, and modulation by cyclothiazide, aniracitam, and thiocyanate. J Neurosci 16:6634-6647.

Patneau DK, Mayer ML (1991) Kinetic analysis of interactions between kainate and AMPA: evidence for activation of a single receptor in mouse hippocampal neurons. Neuron 6:785-798.

Patneau DK, Vyklicky L, Mayer NE (1993) Hippocampal neurons exhibit cyclothiazide-sensitive rapidly desensitizing responses to kainate. J Neurosci 13:3496-3509.

Premkumar LS, Auerbach A (1997) Stoichiometry of recombinant N-methylD-aspartate channels inferred from single-channel current patterns. J Gen Physiol 110:485-502.

Robert A, Irizarry SN, Hughes TE, Howe JR (2001) Subunit interactions and AMPA receptor desensitization. J Neurosci 21:5574-5586.

Rosenmund C, Stern-Bach Y, Stevens CF (1998) The tetrameric structure of a glutamate receptor channel. Science 280:1596-1599.

Sakimura K, Morita T, Kushiya E, Mishna M (1992) Primary structure and expression of the subunit of the glutamate receptor channel selective for kainate. Neuron 8:267-274.

Seeburg PH (1993) The molecular biology of mammalian glutamate receptors. Trends Pharmacol 14:297-303.

Sekiguchi M, Fleck MW, Mayer ML, Takeo J, Chiba Y, Yamashita S, Wada K (1997) A novel allosteric potentiator of AMPA receptors: 4-[2-(phenylsulfonylamino)ethylthio]-2,6-difluoro-phenoxyacetamide. J Neurosci 17: 5760-5771.

Smith TC, Howe JR (2000) Concentration-dependent substate behavior of native AMPA receptors. Nat Neurosci 3:992-997.

Stern-Bach Y, Bettler B, Hartley M, Sheppard PO, O’Hara PJ, Heinemann SF (1994) Agonist selectivity of glutamate receptors is specified by two domains structurally related to bacterial amino acid-binding proteins. Neuron 13:1345-1357.

Stern-Bach Y, Russo S, Neuman M, Rosemund C (1998) A point mutation in the glutamate binding site blocks desensitization of AMPA receptors. Neuron 21:907-918.

Sun Y, Olson R, Horning M, Armstrong N, Mayer M, Gouaux E (2002) Mechanism of glutamate receptor desensitization. Nature 417:245-253.

Swanson GT, Gereau IV RW, Green T, Heinemann SF (1997) Identification of amino acid residues that control functional behavior in GluR5 and GluR6 kainate receptors. Neuron 19:913-926.

Swanson GT, Green T, Sakai R, Contractor A, Che W, Kamiya H, Heinemann SF (2002) Differential activation of individual subunits in heteromeric kainate receptors. Neuron 34:589-598.

Tu LW, Deutsch C (1999) Evidence for dimerization of dimers in K+ channel assembly. Biophys J 76:2004-2017.

Tygesen CK, Jorgensen M, Andersen PH (1995) The importance of two specific domains in ligand binding to the AMPA/kainate glutamate receptors GluR2 and GluR6. FEBS Lett 363:184-188.

Werner P, Voigt M, Keinanen K, Wisden W, Seeburg PH (1991) Cloning of a putative high-affinity kainate receptor expressed predominantly in hippocampal $\mathrm{CA}_{3}$ cells. Nature 351:742-744.

Wong LA, Mayer ML (1993) Differential modulation by cyclothiazide and concanavalin A of desensitization at native $\alpha$-amino-3-hydroxy-5-methyl4-isoxazolepropionic acid- and kainate-preferring glutamate receptors. Mol Pharmacol 44:504-510.

Yamada KA, Tang C-M (1993) Benzothiadiazides inhibit rapid glutamate receptor desensitization and enhance glutamatergic synaptic currents J Neurosci 13:3904-3915. 